\title{
Article \\ Erectile Dysfunction Is the Main Correlate of Depression in Men with Chronic Spinal Cord Injury
}

\author{
Arcangelo Barbonetti ${ }^{1} * * \mathbb{D}$, Settimio $\mathrm{D}^{\prime}$ Andrea ${ }^{1}$, Chiara Castellini ${ }^{1}$, Maria Totaro ${ }^{1}$, Mario Muselli ${ }^{2}$, \\ Francesca Cavallo ${ }^{3}$, Giorgio Felzani ${ }^{3}$, Stefano Necozione ${ }^{2}$ and Sandro Francavilla ${ }^{1}$ \\ 1 Andrology Unit, Department of Life, Health and Environmental Sciences, University of L'Aquila, \\ 67100 L'Aquila, Italy; dandrea.settimio@alice.it (S.D.); chiara.castellini@univaq.it (C.C.); \\ maria.totaro@outlook.com (M.T.); sandro.francavilla@univaq.it (S.F.) \\ 2 Epidemiology Division, Department of Life, Health and Environmental Sciences, University of L'Aquila, \\ 67100 L'Aquila, Italy; mario.muselli@graduate.univaq.it (M.M.); stefano.necozione@univaq.it (S.N.) \\ 3 Spinal Unit, San Raffaele Institute of Sulmona, 67039 Sulmona, Italy; francycavallo@hotmail.it (F.C.); \\ giorgio.felzani@sanraffaele.it (G.F.) \\ * Correspondence: arcangelo.barbonetti@univaq.it; Tel.: +39-0862-368338
}

Citation: Barbonetti, A.; D'Andrea, S.; Castellini, C.; Totaro, M.; Muselli, M.; Cavallo, F.; Felzani, G.; Necozione S.; Francavilla, S. Erectile Dysfunction Is the Main Correlate of Depression in Men with Chronic Spinal Cord Injury. J. Clin. Med. 2021, 10, 2090. https:// doi.org/10.3390/jcm10102090

Academic Editor: Matthias D. Hofer

Received: 26 March 2021

Accepted: 8 May 2021

Published: 13 May 2021

Publisher's Note: MDPI stays neutral with regard to jurisdictional claims in published maps and institutional affiliations.

Copyright: (c) 2021 by the authors. Licensee MDPI, Basel, Switzerland. This article is an open access article distributed under the terms and conditions of the Creative Commons Attribution (CC BY) license (https:// creativecommons.org/licenses/by/ $4.0 /)$.

\begin{abstract}
Depression is the most prevalent psychological issue after a spinal cord injury (SCI) and is associated with noticeable disability, mortality and health expenditure. As SCI mainly occurs in sexually active men at a young age, and can lead to them suffering from an organic neurogenic erectile dysfunction (ED), we supposed that ED could be a major correlate of depressive status in men with SCI. As documented by a Beck Depression Inventory-II (BDI-II) score $\geq 14$, depression was reported in 17 out of 57 men with a chronic SCI (29.8\%). They exhibited a significantly higher prevalence of ED and a more severe bowel and bladder dysfunction when compared to the group without depression. At the multiple logistic regression analysis, depression showed a significant independent association with $\mathrm{ED}(\mathrm{OR}=19.0,95 \% \mathrm{CI}: 3.1,203.3 ; p=0.004)$ and, to a lesser extent, with a severe impairment of bowel and bladder function (OR $=0.84 ; 95 \% \mathrm{CI}: 0.72,0.94 ; p=0.01$ ). Depression was observed in $43.7 \%$ of men with ED and only in $12.0 \%$ of those without ED $(p=0.002)$. In conclusion, healthcare providers should give the right level of importance to the management of ED in men with SCI, as this represents a major independent correlate of depression, which, in turn, might hinder physical rehabilitation and exacerbate physical health issues related to SCI.
\end{abstract}

Keywords: impotence; mood disorders; paraplegia; psychological health; quadriplegia; sexual dysfunction

\section{Introduction}

In studies using diagnostic interviews, the prevalence of major depression in patients with SCI ranged from $9.8 \%$ to $37.5 \%$ [1]. Similar prevalence rates have been reported in both rehabilitative settings for SCI (20-43\%) and community-dwelling contexts (11-60\%) when screening tools for depression were used [2]. Nevertheless, in the US population, the 1-year prevalence of major depression was 6.7\% [3], therefore resizing depression as a major concern in people with SCI.

Left untreated, depressive symptoms may become chronic and negatively impact the health-related quality-of-life for people with SCI, leading to secondary health disorders with recurrent hospitalizations [4], poorer functional gains [5], and reduced life expectancy [6]. Major depression predicts all-cause mortality after a SCI [7]; meanwhile, the suicide rate among this population is believed to be up to five times higher than expected in the general population in the US, Europe, and Australia [8,9]. The high prevalence and clinical weight of depression promoted research in the field of SCI, focusing on risk and protective factors for this relevant condition. Alcohol and drug misuse were significantly predictive for severe SCIrelated depression [10]. A large, systematic review of observational data from 3172 adults with 
SCI identified relevant psychosocial correlates of post-injury depression [11]. While personal variables, such as affective feelings and SCI-specific thoughts, had the strongest relationships with depression, the acceptance of disability, life satisfaction, participation in the community and the environmental support displayed medium to strong associations [11]. These findings suggested the need to undertake early interventions and prevention approaches focusing on the evaluation and management of risk factors for psychosocial issues to limit the impact of SCI-related depression [12].

Attention has, to date, focused on psychosocial, demographic, and neurologic issues as putative major correlates of depressive symptoms in patients with SCI [5,10-12], largely neglecting the role of sexual dysfunction. As young men generally get involved in riskier activities than women, they are more prone to accidents, and consequently to traumatic SCI. Accordingly, $80 \%$ of SCI occurs in men at an average age that has increased from 29 years during the 1970s to 43 since 2015 [13]. Thus, SCI mainly occurs in sexually active young men for whom sexual function represents a major determinant of their quality of life, interpersonal relationships [14], psychological wellbeing [15], and life satisfaction [13,16]. Erectile dysfunction (ED), defined as "the inability to achieve and/or maintain penile erection sufficient for satisfactory sexual performance" [17], represents the main determinant of both psychological distress [15] and life dissatisfaction [16] in men with SCI. Androgen deficiency and hypovitaminosis $\mathrm{D}$ are regarded as further putative determinants of depression in the general population [18-20] and in SCI individuals [21].

In this context, the weight of ED among the putative determinants of depression in men with SCI remains to be clarified. Due to the high prevalence of neurologic ED following SCI $[15,16]$, we surmise that ED could represent a key independent correlate of depressive symptoms in this population.

\section{Materials and Methods}

Fifty-seven men, aged $47.0 \pm 17.4$ years, admitted to a rehabilitation program at the San Raffaele Institute of Sulmona (Italy) because of traumatic SCI, were included in the study. Each patient gave informed consent for diagnostic evaluations. All enrolled men had a neurologically stable SCI lasting more than 1 year. None of them was under replacement therapy with testosterone or suffered from cognitive or communication disorders that could compromise the validity of their responses in the questionnaires.

Patients underwent clinical and neurologic evaluations by the same trained physician. In keeping with the International Standards for Neurological Classification of SCI from the American Spinal Injury Association (ASIA) and ASIA Impairment Scale (AIS) [22,23], patients with a complete loss of both motor and sensory function in the lowest sacral segment were categorized as grade A, whereas those with an incomplete SCI were categorized as grades B to D. Grade B: motor complete lesion with preservation of some sensation below the SCI level; grade C: preservation of both some sensation and motor function, with $50 \%$ of the muscles below the SCI level unable to move against gravity; grade D: ability of more than $50 \%$ of the muscles below the SCI level to move against gravity. Functional independence degree in activities of daily living (ADL) was assessed by the Spinal Cord Independence Measure (SCIM). This is a 19-item tool measuring the functional independence degree in performing ADL [24,25]. The SCIM weighs each function separately, giving a total score ranging from 0 (totally dependent) to 100 (totally independent). Bladder and bowel dysfunction are explored by the 6th and 7th item of the SCIM, respectively, providing a bowel/bladder SCIM sub-score.

Leisure time physical activity (LTPA) was assessed in min/week with the LTPA Questionnaire for people with SCI (LTPAQ-SCI) [26], as previously described [27-29]. An intensity classification chart allowed for discrimination between mild, moderate, and heavy intensity LTPA, according to the perceived effort. For each intensity degree, patients reported the number of days, over the last 7 days, which they performed LTPA at each intensity. Next, they reported the min/day they spent performing LTPA at that intensity. Finally, the total number of min/weeks of activity at each intensity was calculated as 
follows: number of days of activity $\times$ number of min of activity. Only the total LTPAQ-SCI score was used for analyses, as this was significantly correlated with mild, moderate, and heavy LTPAQ-SCI sub-scores [30].

According to the recommendations from the National Institute on Disability and Rehabilitation Research [31], the presence and intensity of pain was assessed by the Numerical Rating Scale (NRS). Patients rated their pain on a scale from 0 (no pain) to 10 (the worst possible pain).

Upon admission, the presence and severity of significant medical comorbidity was scored using a web-based calculator (http:/ / www.mdcalc.com/charlson-comorbidityindex-cci (accessed on 12 May 2021)) of the age-adjusted Charlson Comorbidity Index (CCI) [32]. The CCI weights medical diagnoses for severity according to the patient's age and provides an overall index of comorbidity. However, no patient had acute or chronic coexisting diseases which could hinder the rehabilitation program.

Body weight was measured with a professional mechanical chair scale Mod. DM2 (Wunder SA BI Srl, Monza, Italia). Height was determined with an elastic tape, segmentally measuring the distances between heel and knee, knee and hip, hip and head. Body mass index (BMI) was calculated in $\mathrm{kg} / \mathrm{m}^{2}$.

Erectile dysfunction was assessed using an abridged, 5-item version of the International Index of Erectile Function (IIEF)-5 [33]. The first four items focused on erectile function while the fifth item focused on intercourse satisfaction. IIEF-5 results were able to identify the presence or absence of ED according to the National Institute of Health's definition [17]. For each five items, a score from 0 to 5 was provided, to discriminate patients with (score $\leq 21)$ and without (score from 22 to 25) ED.

The presence of depressive symptoms and their severity were assessed by the interviewerassisted self-report Beck Depression Inventory-II (BDI-II) [34] which was administered at admission by the same psychologist (F.C.). The BDI-II is a 21-item screening tool for depressive symptoms [19,35], largely used for people with SCI [21,36,37]. Previously published cut-off points identified patients with "no depression" (score $<14$ ) and "mild to severe depression" $(\geq 14)[20,34]$.

A fasting, morning venous blood sample was obtained from each patient between 8.00 and $9.00 \mathrm{a} . \mathrm{m}$. Total testosterone levels were measured with a chemiluminescence immunoassay, using a kit from Ortho Clinical Diagnostics (Johnson \& Johnson, New Brunswick, NJ, USA). The lower limit of detection for testosterone measurement was $0.03 \mathrm{nmol} / \mathrm{L}$ and the within- and between-assay coefficients of variation (CV) were $2.5 \%$ and $4.9 \%$, respectively. Sex hormone binding globulin (SHBG) was quantified by a chemiluminescence immunoassay, using a kit from Medical Systems (Genova, Italy). Albumin was measured by spectrophotometry using a colorimetric assay kit from Roche Diagnostics (Monza, Italy). The levels of calculated free testosterone were derived from total testosterone, SHBG, and albumin as previously described [38], using a web-based calculator (http:/ / www.issam.ch/freetesto.htm (accessed on 12 May 2021)). Serum 25-hydroxy vitamin $\mathrm{D}(25(\mathrm{OH}) \mathrm{D})$ levels were quantified using a chemiluminescent immunoassay (LIAISON; DiaSorin, Saluggia, Italy) with an intra- and inter-assay CV of $4.5 \%$ and $8.5 \%$, respectively. All the other biochemical/hematologic parameters were measured using standard methods and commercial kits (Instrumentation Laboratory Co., Bedford, MA, USA).

Statistical analysis was carried out using the R statistical software (version 3.5.0, The $\mathrm{R}$ Foundation for Statistical Computing, Vienna, Austria). After ascertaining the nonnormal distribution of data with the Shapiro-Wilk test, the Wilcoxon rank-sum test was used to evaluate differences in continuous variables between participants dichotomized as depressed (BDI-II score $\geq 14$ ) or non-depressed (BDI-II score $<14$ ). Proportional differences were assessed by the chi-square test or the Fisher's exact test, as appropriate. Multiple logistic regression analyses with odds ratios (ORs) and 95\% confidence intervals (CIs) were performed to identify independent associations with depression. 


\section{Results}

Depression was reported in $29.8 \%$ (17 out of 57 men) of the study population. When men were categorized by depression status, according to BDI-II score (Table 1), the depressed group exhibited significantly lower levels of both total and calculated free testosterone as well as vitamin $\mathrm{D}$, a higher prevalence of ED, a more severe bowel and bladder dysfunction, and were engaged in a poorer, albeit not significantly different, LTPA when compared to non-depressed men. Specific SCI-related variables, such as level and completeness of the injury and the impairment degree in the global functional independence, were not significantly different between the two groups, and this was also the case for the demographic variables, including education and marital/partner status.

Table 1. Characteristics of the study population categorized by depression status at the Beck Depression Inventory-II.

\begin{tabular}{|c|c|c|c|}
\hline \multirow[b]{2}{*}{ Characteristics } & \multicolumn{2}{|c|}{ Beck Depression Inventory-II Score } & \multirow[b]{2}{*}{$p$ Value } \\
\hline & $\begin{array}{c}<14 \\
\text { (Not Depressed) } \\
\mathrm{N}=40\end{array}$ & $\begin{array}{c}\geq 14 \\
\text { (Depressed) } \\
\mathbf{N}=17\end{array}$ & \\
\hline \multicolumn{4}{|l|}{ Demographic and lifestyle variables } \\
\hline Age (years) & $41.5(21.0-81.0)$ & $52.0(20.0-76.0)$ & 0.5 \\
\hline \multicolumn{4}{|l|}{ Education-n $(\%)$} \\
\hline Primary school & $11(27.5)$ & $7(41.2)$ & 0.6 \\
\hline High school & $24(60.0)$ & $9(53.0)$ & \\
\hline University & $5(12.5)$ & $1(5.8)$ & \\
\hline \multicolumn{4}{|l|}{ Marital/partner status- $n(\%)$} \\
\hline Single & $18(45.0)$ & $6(35.3)$ & 0.7 \\
\hline Married & $16(40.0)$ & $7(41.3)$ & \\
\hline Divorced/separeted & $4(10.0)$ & $2(11.7)$ & \\
\hline Widowed & $2(5.0)$ & $2(11.7)$ & \\
\hline LTPA (min/week) & $560(35-1225)$ & $245(35-1015)$ & 0.08 \\
\hline \multicolumn{4}{|l|}{ Clinical and injury-related characteristics } \\
\hline $\mathrm{BMI}\left(\mathrm{Kg} / \mathrm{m}^{2}\right)$ & $24.6(15.2-37.2)$ & $25.4(12.3-32.7)$ & 0.5 \\
\hline Charlson Comorbidity Index score & $2(0-8)$ & $3(0-7)$ & 0.2 \\
\hline BDI-II score & $6.5(1-13)$ & $14(14-23)$ & $<0.0001$ \\
\hline Psychotropic drugs- $n(\%)$ & $12(30.0)$ & $6(35.3)$ & 0.9 \\
\hline Duration of injury (years) & $11.2(1.5-37.0)$ & $7.0(1.1-24.0)$ & 0.1 \\
\hline \multicolumn{4}{|l|}{ Lesion motor completeness- $n(\%)$} \\
\hline Complete (AIS A+B) & $25(62.5)$ & $14(82.3)$ & 0.2 \\
\hline Incomplete (AIS C+D) & $15(37.5)$ & $3(17.7)$ & \\
\hline \multicolumn{4}{|l|}{ Level of the lesion- $n(\%)$} \\
\hline Cervical Spine & $19(47.5)$ & $11(64.7)$ & 0.3 \\
\hline Thoracic-lumbar Spine & $21(52.5)$ & $6(35.3)$ & \\
\hline SCIM score & $38.0(11.0-56.0)$ & $35.0(10.0-69.0)$ & 0.4 \\
\hline Bowel/bladder SCIM sub-score * & $22.0(0.0-25.0)$ & $9.0(0.0-20.0)$ & 0.001 \\
\hline Pain Intensity (NRS score) & $3.0(0.0-10.0)$ & $3.0(0.0-8.0)$ & 0.9 \\
\hline Erectile dysfunction $-n(\%)$ & $18(45.0)$ & $14(82.3)$ & 0.02 \\
\hline \multicolumn{4}{|l|}{ Blood biometric measures } \\
\hline Total testosterone $(\mathrm{ng} / \mathrm{dL})$ & $404.5(111.0-713.0)$ & $268.0(25.0-694.0)$ & 0.03 \\
\hline Calculated free testosterone $(\mathrm{pg} / \mathrm{mL})$ & $118.1(27.8-241.1)$ & $65.0(2.9-162.9)$ & 0.02 \\
\hline Vitamin D (ng/mL) & $16.3(4.1-34.4)$ & $11.1(4.4-22.6)$ & 0.02 \\
\hline \multicolumn{4}{|l|}{ Season of evaluation- $n(\%)$} \\
\hline Autumn/winter & $24(60.0)$ & $7(41.2)$ & 0.3 \\
\hline Spring/summer & $16(40.0)$ & $10(58.8)$ & \\
\hline
\end{tabular}

Data were expressed as median (minimum-maximum) for continuous parameters and as number (\%) when categorical. ${ }^{*}$ The bowel/bladder SCIM sub-score included the 6th and 7th items of the SCIM. Abbreviations: AIS, American spinal injury association (ASIA) Impairment Scale, BDI-II, Beck Depression Inventory-II, BMI, body mass index, LTPA, leisure time physical activity, NRS, numeric rating score, SCIM Spinal Cord Independence Measure.

At the multiple logistic regression analysis (Table 2) which included variables which were significantly different between depressed and non-depressed men (Table 1), depression exhibited a significant independent association with ED and, to a lesser extent, with a 
more severe impairment of bowel and bladder function. No significant associations were found with testosterone or vitamin D levels (Table 2).

Table 2. Multiple logistic regression analysis of the independent correlates of depression in men with chronic spinal cord injury.

\begin{tabular}{lcc}
\hline & \multicolumn{2}{c}{ Depression (BDI-II Score $\geq \mathbf{1 4})$} \\
\cline { 2 - 3 } & OR $(\mathbf{9 5 \%}$ CI) & $p$ Value \\
\hline Erectile dysfunction (IIEF-5 score $\leq 21)$ & $19.0(3.1 ; 203.3)$ & 0.004 \\
\hline Bowel/bladder SCIM sub-score & $0.84(0.72 ; 0.94)$ & 0.01 \\
\hline Calculated free testosterone $(\mathrm{pg} / \mathrm{mL})$ & $0.98(0.96 ; 1.0)$ & 0.07 \\
\hline Vitamin D $(\mathrm{ng} / \mathrm{mL})$ & $0.96(0.82 ; 1.1)$ & 0.6 \\
\hline To convert the values for calculated free testosterone to pmol/L, multiply by 3.467. Abbreviations: BDI-II, Beck
\end{tabular}

Depression Inventory-II; CI, confidence intervals; IIEF-5, international index of erectile function 5; OR, odds ratio.

As shown in Figure 1, depression was reported by 14 out of the 32 (43.7\%) men with $\mathrm{ED}$ and only by 3 out of the 25 men $(12.0 \%)$ without $\mathrm{ED}(p=0.002)$.

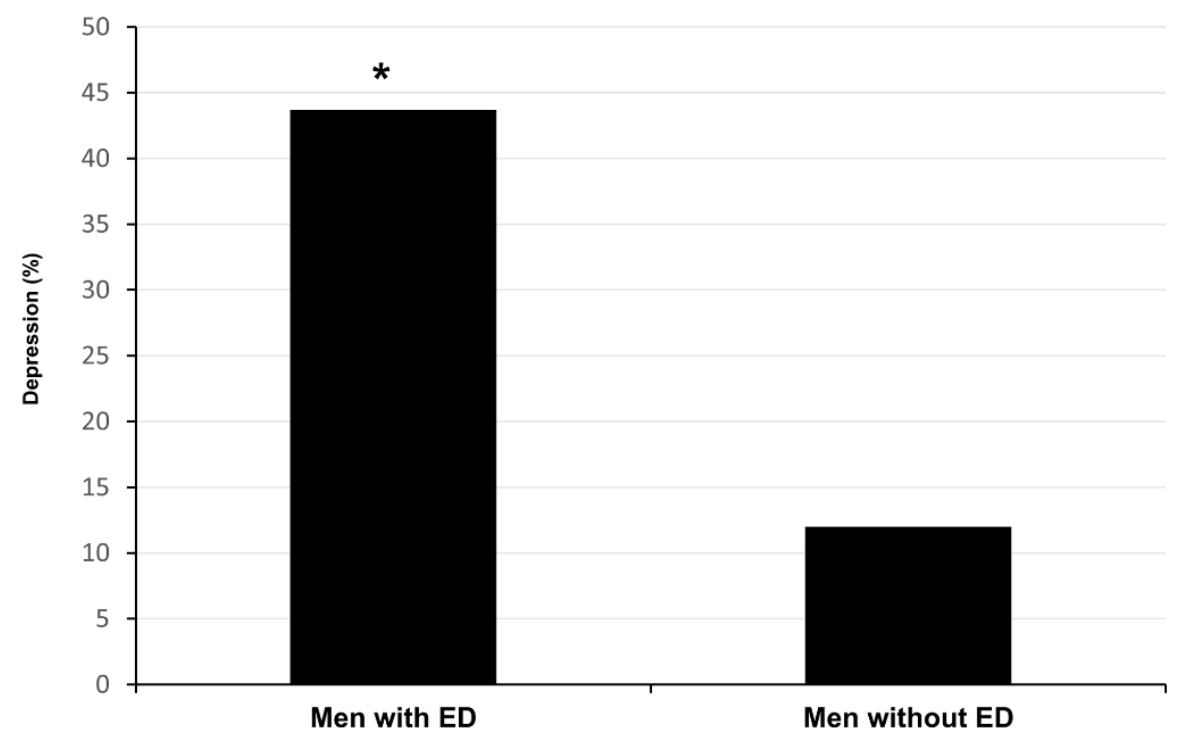

Figure 1. Percentage of spinal cord injured, depressed men with and without erectile dysfunction (ED). ${ }^{*} p=0.002$.

\section{Discussion}

It is well known that psychological disorders are documented in able-bodied men who sought medical care for ED [39,40], showing a 2.4-fold increased risk of depression [41]. However, whether psychological distress represents an independent risk factor for ED rather than a consequence or a coexisting condition of ED is not easily established [41]. Men with SCI are affected by an organic neurogenic ED relied on the level and completeness of neurologic lesion [15]: this would explain the lack of a significant association between ED prevalence and age in this population [15]. In this light, SCI could represent an interesting clinical model to explore a possible causative link between ED and depression. Here, we showed that ED was significantly more prevalent in men with SCI reporting depressive symptoms compared to those without depression. In the multiple regression analysis, ED was the most relevant independent correlate of depressive symptoms.

Men with a traumatic SCI suffer from a sudden, violent and, in most cases, irreversible form of tragic nonlethal disease. They need to manage various problems, which will definitively affect their whole lives. Physical restrictions and the loss of functional independence are expected to represent relevant determinants of depression [42]. Therefore, it is expected 
that men with a more severe locomotor disability (that is tetraplegia) should exhibit a higher risk of depression compared to men with paraplegia. On the contrary, in our study of men with chronic SCI, neurological characteristics, including the level and completeness of the lesion and the physical, functional independence, were not significantly different between depressed and not depressed men, as previously reported $[7,10,37,43-46]$. This is in line with our previous study, in which men with a cervical lesion, despite lower functional independence, exhibited significantly lower psychological distress than those with thoracolumbar lesions [15]. Our findings also agree with previous reports showing that disability degree did not affect or predict perceived quality of life in people with SCI [47-49].

Indeed, paraplegic status was associated with a significantly higher prevalence of ED compared to tetraplegia [15]. ED, which is more prevalent and severe in thoraco-lumbar $\mathrm{SCI}$ than cervical lesions, might have a pivotal effect in favoring depressive symptoms, as well as life dissatisfaction, despite higher functional independence in men with a thoracolumbar lesion.

Besides ED, bowel/bladder dysfunction was more severe in men with depressive symptoms. While bowel and bladder dysfunction represent a relevant concern of active patients with SCI [50], potentially contributing to their psychological distress, the association of physical functional independence with depression is unclear. In a large survey of 849 patients with chronic SCI ( $76.0 \%$ males), the rate of a probable major depression disorder, assessed by The Patient Health Questionnaire-9 (PHQ-9), did not differ according to injury level (paraplegia vs. tetraplegia), injury severity or functional independence measure (FIM) discharge scores, which included sphincter control [1]. On the contrary, fecal impaction, a main trigger of autonomic dysreflexia, resulting from SCI-related neurogenic bowel dysfunction, was linked to depression [51] as assessed by the BDI score and was closely related to the patient's ability to perform self-catheterization [43]. The causal link between depression and neurogenic bowel and/or bladder dysfunction outcomes is not yet elucidated.

The degree of bowel/bladder dysfunction in our survey maintained a significant independent association with depression at the multiple logistic regression analysis, although to a much lower extent than ED, thus resizing its potential relevance as a risk factor for depressive symptoms in men with SCI. In a previous study, we demonstrated that the degree of bowel/bladder independence was only significantly correlated with the degree of life satisfaction, among the SCI-related variables; this association was lost at the multiple logistic regression model adjusted for the sexual satisfaction score of the Lisat-9 questionnaire [16]. We surmised that life satisfaction was not directly affected by the neurogenic impairment of bowel and/or bladder function, which adversely impacted sexual well-being. Indeed, anal sphincter dysfunction causing recurrent accidental bowel leakage during sexual activity may result in an obvious embarrassment in life relationships. Similarly, sexual intercourse may be hindered or impeded by the need for an indwelling catheter because of severe neurogenic bladder dysfunction. Here, we extended this conclusion, demonstrating that neurogenic bowel/bladder dysfunction also has an independent effect on symptoms of depression.

Interestingly, total and calculated free testosterone levels were significantly lower in spinal cord injured men with depression when compared to the non-depressed group, but this association was no longer present when the logistic regression model was adjusted for ED. The contribution of erectile function, irrespective of the androgen status, is not surprising. ED represents a major attribute of androgen deficiency in the general population [52], but not in men with SCI [30] who, as mentioned, suffer from a purely organic neurogenic ED depending on the level and completeness of SCI [15]. ED would accordingly contribute to depression independently of testosterone levels.

We previously demonstrated that vitamin D levels were inversely associated with the risk of depression in people with SCI [21]. In the present study, depressed men with SCI exhibited lower vitamin D levels compared to men who were not depressed. However, this association was lost after adjusting for ED and sphincter dysfunction. Depression 
itself may contribute to lower vitamin D levels by reducing outdoor physical activity and, consequently, sunlight exposure. Hence, other than a direct causal role of hypovitaminosis $\mathrm{D}$ in depression, both conditions could represent markers of poor health status, without a direct interaction.

This study has some limitations that must be considered. The cross-sectional study design could not establish the cause-effect relationship between ED and depression. Moreover, the IIEF-5 was not validated for SCI and, therefore, in the present population it does not discriminate between reflexogenic and psychogenic erection. However, IIEF-5 has already been used for men with SCI $[53,54]$. Finally, the sample size of our series was quite small, especially in the depressed group, but was sufficient to demonstrate probable significant independent associations due to the high prevalence of the investigated disorders among men with chronic SCI.

In conclusion, ED and, to a lesser extent, bowel/bladder dysfunction in men with SCI, showed a significant and independent association with depression, pointing to a possible causal role of ED on depressive symptoms in this population and confirming that, in sexually active men, the restoration of sexual life could rate as a high priority. Longitudinal studies should explore whether the appropriate management of ED and sphincter dysfunction might prevent depression while fostering life satisfaction in men with SCI.

Author Contributions: Conceptualization, A.B., F.C. and S.D.; Methodology, A.B. and S.D.; Software, A.B., M.M. and S.D.; Validation, A.B. and S.F.; Formal Analysis, A.B. and S.D.; Investigation, A.B., F.C., G.F. and M.T.; Data Curation, A.B. and C.C.; Writing and Original Draft Preparation, S.D. and S.F.; Writing, Review and Editing, A.B. and S.F.; Supervision, S.N. All authors have read and agreed to the published version of the manuscript.

Funding: This research was funded by MINISTERO DELL'UNIVERSITÀ E DELLA RICERCA, ITALY (PRIN 2017), grant number: 2017XLFJAX.

Institutional Review Board Statement: The study was conducted according to the guidelines of the Declaration of Helsinki and approved by the local Ethics Committee of the University of L'Aquila.

Informed Consent Statement: Written informed consent has been obtained from the patients to publish this paper.

Data Availability Statement: All data are contained within the article. No additional information is available for data sharing.

Conflicts of Interest: The authors declare no conflict of interest.

\section{References}

1. Bombardier, C.H.; Richards, J.S.; Krause, J.S.; Tulsky, D.; Tate, D.G. Symptoms of major depression in people with spinal cord injury: Implications for screening. Arch. Phys. Med. Rehabil. 2004, 85, 1749-1756. [CrossRef] [PubMed]

2. Craig, A.; Tran, Y.; Middleton, J. Psychological morbidity and spinal cord injury: A systematic review. Spinal Cord 2009, 47, 108-114. [CrossRef] [PubMed]

3. Kessler, R.C.; Chiu, W.T.; Demler, O.; Merikangas, K.R.; Walters, E.E. Prevalence, severity, and comorbidity of 12-month DSM-IV disorders in the National Comorbidity Survey Replication. Arch. Gen. Psychiatry 2005, 62, 617-627. [CrossRef]

4. January, A.M.; Zebracki, K.; Chlan, K.M.; Vogel, L.C. Mental health and risk of secondary medical complications in adults with pediatric-onset spinal cord injury. Top. Spinal Cord Inj. Rehabil. 2014, 20, 1-12. [CrossRef]

5. Arango-Lasprilla, J.C.; Ketchum, J.M.; Starkweather, A.; Nicholls, E.; Wilk, A.R. Factors predicting depression among persons with spinal cord injury 1 to 5 years post injury. Neuro Rehabil. 2011, 29, 9-21. [CrossRef]

6. Hartoonian, N.; Hoffman, J.M.; Kalpakjian, C.Z.; Taylor, H.B.; Krause, J.K.; Bombardier, C.H. Evaluating a spinal cord injuryspecific model of depression and quality of life. Arch. Phys. Med. Rehabil. 2014, 95, 455-465. [CrossRef] [PubMed]

7. Krause, J.S.; Carter, R.E.; Pickelsimer, E.E.; Wilson, D. A prospective study of health and risk of mortality after spinal cord injury. Arch. Phys. Med. Rehabil. 2008, 89, 1482-1491. [CrossRef]

8. DeVivo, M.J.; Black, K.J.; Richards, S.; Stover, S.L. Suicide following spinal cord injury. Paraplegia 1991, 29, 620-627. [CrossRef]

9. Judd, F.K.; Brown, D.J. Suicide following acute traumatic spinal cord injury. Paraplegia 1992, 30, 173-177. [CrossRef] [PubMed]

10. Williams, R.T.; Wilson, C.S.; Heinemann, A.W.; Lazowski, L.E.; Fann, J.R.; Bombardier, C.H. PRISMS Investigators. Identifying depression severity risk factors in persons with traumatic spinal cord injury. Rehabil. Psychol. 2014, 59, 50-56. [CrossRef] [PubMed] 
11. Kraft, R.; Dorstyn, D. Psychosocial correlates of depression following spinal injury: A systematic review. J. Spinal Cord Med. 2015, 38, 571-583. [CrossRef] [PubMed]

12. de Roon-Cassini, T.A.; Mancini, A.D.; Rusch, M.D.; Bonanno, G.A. Psychopathology and resilience following traumatic injury: A latent growth mixture model analysis. Rehabil. Psychol. 2010, 55, 1-11. [CrossRef]

13. National Spinal Cord Injury Statistical Center. Facts and Figures at a Glance; University of Alabama at Birmingham: Birmingham, AL, USA, 2020.

14. Anderson, K.D.; Borisoff, J.F.; Johnson, R.D.; Stiens, S.A.; Elliott, S.L. The impact of spinal cord injury on sexual function: Concerns of the general population. Spinal Cord 2007, 45, 328-337. [CrossRef] [PubMed]

15. Barbonetti, A.; Cavallo, F.; Felzani, G.; Francavilla, S.; Francavilla, F. Erectile dysfunction is the main determinant of psychological distress in men with spinal cord injury. J. Sex. Med. 2012, 9, 830-836. [CrossRef] [PubMed]

16. D'Andrea, S.; Minaldi, E.; Castellini, C.; Cavallo, F.; Felzani, G.; Francavilla, S.; Francavilla, F.; Barbonetti, A. Independent Association of Erectile Dysfunction and Low Testosterone Levels with Life Dissatisfaction in Men with Chronic Spinal Cord Injury. J. Sex. Med. 2020, 17, 911-918. [CrossRef] [PubMed]

17. NIH Consensus Conference. Impotence. NIH Consensus Development Panel on Impotence. JAMA 1993, 270, 83-90. [CrossRef]

18. Zarrouf, F.A.; Artz, S.; Griffith, J.; Sirbu, C.; Kommor, M. Testosterone and depression: Systematic review and meta-analysis. J. Psychiatr. Pract. 2009, 15, 289-305. [CrossRef]

19. Ganji, V.; Milone, C.; Cody, M.M.; McCarty, F.; Wang, Y.T. Serum vitamin D concentrations are related to depression in young adult US population: The Third National Health and Nutrition Examination Survey. Int. Arch. Med. 2010, 3, 29. [CrossRef]

20. Lee, D.M.; Tajar, A.; O’Neill, T.W.; O'Connor, D.B.; Bartfai, G.; Boonen, S.; Bouillon, R.; Casanueva, F.F.; Finn, J.D.; Forti, G.; et al. Lower vitamin D levels are associated with depression among community-dwelling European men. J. Psychopharmacol. 2011, 25, 1320-1328. [CrossRef] [PubMed]

21. Barbonetti, A.; Cavallo, F.; D'Andrea, S.; Muselli, M.; Felzani, G.; Francavilla, S.; Francavilla, F. Lower Vitamin D Levels Are Associated with Depression in People with Chronic Spinal Cord Injury. Arch. Phys. Med. Rehabil. 2017, 98, 940-946. [CrossRef]

22. Maynard, F.M., Jr.; Bracken, M.B.; Creasey, G.; Ditunno, J.F., Jr.; Donovan, W.H.; Ducker, T.B.; Garber, S.L.; Marino, R.J.; Stover, S.L.; Tator, C.H.; et al. International Standards for Neurological and Functional Classification of Spinal Cord Injury. American Spinal Injury Association. Spinal Cord 1997, 35, 266-274. [CrossRef]

23. Kirshblum, S.C.; Burns, S.P.; Biering-Sorensen, F.; Donovan, W.; Graves, D.E.; Jha, A.; Johansen, M.; Jones, L.; Krassioukov, A.; Mulcahey, M.J.; et al. International standards for neurological classification of spinal cord injury (revised 2011). J. Spinal Cord Med. 2011, 34, 535-546. [CrossRef]

24. Catz, A.; Itzkovich, M.; Agranov, E.; Ring, H.; Tamir, A. SCIM-Spinal cord independence measure: A new disability scale for patients with spinal cord lesions. Spinal Cord 1997, 35, 850-856. [CrossRef] [PubMed]

25. Anderson, K.; Aito, S.; Atkins, M.; Biering-Sørensen, F.; Charlifue, S.; Curt, A.; Ditunno, J.; Glass, C.; Marino, R.; Marshall, R.; et al. Functional recovery measures for spinal cord injury: An evidence-based review for clinical practice and research. J. Spinal Cord Med. 2008, 31, 133-144. [CrossRef] [PubMed]

26. Ginis, K.A.; Hicks, A.L.; Latimer, A.E.; Warburton, D.E.; Bourne, C.; Ditor, D.S.; Goodwin, D.L.; Hayes, K.C.; McCartney, N.; Mcllraith, A.; et al. The development of evidence-informed physical activity guidelines for adults with spinal cord injury. Spinal Cord 2011, 49, 1088-1096. [CrossRef]

27. Williams, T.L.; Smith, B.; Papathomas, A. The barriers, benefits and facilitators of leisure time physical activity among people with spinal cord injury: A meta-synthesis of qualitative findings. Health Psychol. Rev. 2014, 8, 404-425. [CrossRef] [PubMed]

28. Barbonetti, A.; Vassallo, M.R.; Felzani, G.; Francavilla, S.; Francavilla, F. Association between 25(OH)-vitamin D and testosterone levels: Evidence from men with chronic spinal cord injury. J. Spinal Cord Med. 2016, 39, 246-252. [CrossRef]

29. Barbonetti, A.; Sperandio, A.; Micillo, A.; D'Andrea, S.; Pacca, F.; Felzani, G.; Francavilla, S.; Francavilla, F. Independent Association of Vitamin D with Physical Function in People with Chronic Spinal Cord Injury. Arch. Phys. Med. Rehabil. 2016, 97, 726-732. [CrossRef]

30. Barbonetti, A.; Vassallo, M.R.; Pacca, F.; Cavallo, F.; Costanzo, M.; Felzani, G.; Francavilla, S.; Francavilla, F. Correlates of low testosterone in men with chronic spinal cord injury. Andrology 2014, 2, 721-728. [CrossRef]

31. Bryce, T.N.; Budh, C.N.; Cardenas, D.D.; Dijkers, M.; Felix, E.R.; Finnerup, N.B.; Kennedy, P.; Lundeberg, T.; Richards, J.S.; Rintala, D.H.; et al. Pain after spinal cord injury: An evidence-based review for clinical practice and research. Report of the National Institute on Disability and Rehabilitation Research Spinal Cord Injury Measures meeting. J. Spinal Cord Med. 2007, 30, 421-440. [CrossRef] [PubMed]

32. Charlson, M.; Szatrowski, T.P.; Peterson, J.; Gold, J. Validation of a combined comorbidity index. J. Clin. Epidemiol. 1994, 47, 1245-1251. [CrossRef]

33. Rosen, R.C.; Cappelleri, J.C.; Smith, M.D.; Lipsky, J.; Peña, B.M. Development and evaluation of an abridged, 5-item version of the International Index of Erectile Function (IIEF-5) as a diagnostic tool for erectile dysfunction. Int. J. Impot Res. 1999, 11, 319-326. [CrossRef]

34. Beck, A.T.; Steer, R.A.; Brown, G.K. Manual for the Beck Depression Inventory-II; Psychological Corporation: San Antonio, TX, USA, 1996.

35. Segal, D.L.; Coolidge, F.L.; Cahill, B.S.; O’Riley, A.A. Psychometric properties of the Beck Depression Inventory II (BDI-II) among community-dwelling older adults. Behav. Modif. 2008, 32, 3-20. [CrossRef] 
36. Ataoğlu, E.; Tiftik, T.; Kara, M.; Tunç, H.; Ersöz, M.; Akkuş, S. Effects of chronic pain on quality of life and depression in patients with spinal cord injury. Spinal Cord 2013, 51, 23-26. [CrossRef]

37. Xue, S.; Arya, S.; Embuldeniya, A.; Narammalage, H.; da Silva, T.; Williams, S.; Ravindran, A. Perceived functional impairment and spirituality/religiosity as predictors of depression in a Sri Lankan spinal cord injury patient population. Spinal Cord 2016, 54, 1158-1163. [CrossRef] [PubMed]

38. Vermeulen, A.; Verdonck, L.; Kaufman, J.M. A critical evaluation of simple methods for the estimation of free testosterone in serum. J. Clin. Endocrinol. Metab. 1999, 84, 3666-3672. [CrossRef]

39. Derogatis, L.R.; Meyer, J.K.; King, K.M. Psychopathology in individuals with sexual dysfunction. Am. J. Psychiatry 1981, 138, 757-763. [PubMed]

40. Mallis, D.; Moysidis, K.; Nakopoulou, E.; Papaharitou, S.; Hatzimouratidis, K.; Hatzichristou, D. Psychiatric morbidity is frequently undetected in patients with erectile dysfunction. J. Urol. 2005, 174, 1913-1916. [CrossRef]

41. Liu, Q.; Zhang, Y.; Wang, J.; Li, S.; Cheng, Y.; Guo, J.; Tang, Y.; Zeng, H.; Zhu, Z. Erectile Dysfunction and Depression: A Systematic Review and Meta-Analysis. J. Sex. Med. 2018, 15, 1073-1082. [CrossRef] [PubMed]

42. Williams, R.; Murray, A. Prevalence of depression after spinal cord injury: A meta-analysis. Arch. Phys. Med. Rehabil. 2015, 96, 133-140. [CrossRef] [PubMed]

43. Oh, S.J.; Shin, H.I.; Paik, N.J.; Yoo, T.; Ku, J.H. Depressive symptoms of patients using clean intermittent catheterization for neurogenic bladder secondary to spinal cord injury. Spinal Cord 2006, 44, 757-762. [CrossRef]

44. Migliorini, C.E.; New, P.W.; Tonge, B.J. Comparison of depression, anxiety and stress in persons with traumatic and non-traumatic post-acute spinal cord injury. Spinal Cord 2009, 47, 783-788. [CrossRef] [PubMed]

45. Fann, J.R.; Bombardier, C.H.; Richards, J.S.; Tate, D.G.; Wilson, C.S.; Temkin, N.; PRISMS Investigators. Depression after spinal cord injury: Comorbidities, mental health service use, and adequacy of treatment. Arch. Phys. Med. Rehabil. 2011, 92, 352-360. [CrossRef]

46. Bombardier, C.H.; Fann, J.R.; Tate, D.G.; Richards, J.S.; Wilson, C.S.; Warren, A.M.; Temkin, N.R.; Heinemann, A.W.; PRISMS Investigators. An exploration of modifiable risk factors for depression after spinal cord injury: Which factors should we target? Arch. Phys. Med. Rehabil. 2012, 93, 775-781. [CrossRef]

47. Gerhart, K.A.; Koziol-McLain, J.; Lowenstein, S.R.; Whiteneck, G.G. Quality of life following spinal cord injury: Knowledge and attitudes of emergency care providers. Ann. Emerg. Med. 1994, 23, 807-812. [CrossRef]

48. Stensman, R. Adjustment to traumatic spinal cord injury. A longitudinal study of self-reported quality of life. Paraplegia 1994, 32, 416-422. [CrossRef] [PubMed]

49. McColl, M.A. Expectations of health, independence, and quality of life among aging spinal cord-injured adults. Assist. Technol. 1999, 11, 130-136. [CrossRef] [PubMed]

50. Benevento, B.T.; Sipski, M.L. Neurogenic bladder, neurogenic bowel, and sexual dysfunction in people with spinal cord injury. Phys. Ther. 2002, 82, 601-612. [CrossRef]

51. Liu, C.W.; Huang, C.C.; Chen, C.H.; Yang, Y.H.; Chen, T.W.; Huang, M.H. Prediction of severe neurogenic bowel dysfunction in persons with spinal cord injury. Spinal Cord 2010, 48, 554-559. [CrossRef] [PubMed]

52. Wu, F.C.; Tajar, A.; Beynon, J.M.; Pye, S.R.; Silman, A.J.; Finn, J.D.; O’Neill, T.W.; Bartfai, G.; Casanueva, F.F.; Forti, G.; et al. Identification of late-onset hypogonadism in middle-aged and elderly men. N. Engl. J. Med. 2010, 363, 123-135. [CrossRef]

53. Alexander, M.S.; Brackett, N.L.; Bodner, D.; Elliott, S.; Jackson, A.; Sonksen, J.; National Institute on Disability and Rehabilitation Research. Measurement of sexual functioning after spinal cord injury: Preferred instruments. J. Spinal Cord Med. 2009, 32, 226-236. [CrossRef] [PubMed]

54. Morrison, B.F.; White-Gittens, I.; Smith, S.; St John, S.; Bent, R.; Dixon, R. Evaluation of sexual and fertility dysfunction in spinal cord-injured men in Jamaica. Spinal Cord Ser. Cases 2017, 3, 17026. [CrossRef] [PubMed] 